\title{
Simulation of Partial Interaction for Composite Deck of "Al-SABTEA Bridge" Taking The Influence of Static Vehicle loads
}

\author{
Qassim Yehya Hmood ${ }^{1, a, *}$ and Ali Laftah Abbas ${ }^{1}$ \\ ${ }^{1}$ Civil Engineering Department, University of Diyala, Diyala, Baquba, Iraq. \\ aquassimhamood1970@gmail.com
}

\begin{abstract}
The composite bridge has consisted of different materials such as the girder to be steel or precast that connected with deck concrete slab using shear connectors for working as one. In the present study ALSABTEA bridge rehabilitation of the space of the bridge using the composite steel girder existing composite bridge constructed in Diyala-Iraq in 1981 that designed and constructed to behave as full interaction. Representation of composite steel bridge using finite element approach with different parameters to assess the doing of the composite bridge under the effects of static loading using actual dimensions and mechanical properties. The representation of channel shear connectors through elements of COMBIN39 provided simple and powerful modeling of the connectors in comparison with using elements of the 3D solid types. Examining the push-out test and comparing results with the model established by ANSYS proved the proposed numerical model could represent the shear connector's behavior. The difference is small $(2.5 \%$ to $3.7 \%)$ between the model by using the representation shear connector as solid element and combined 39 also, the difference in the results of displacement is small (5\%) between the experimental test and model established by ANSYS. The effect has been studied included. Partial and full interaction of Al-SABTEA Bridge under the effects of Static loadings applied at bridge based on Iraqi specification where the final assessment the results deflection within permissible limits according to all models.
\end{abstract}

Keywords: ANSYS, Finite element, Composite steel-concrete girder, shear connector.

\section{Introduction}

The term composite structure means that two or more different structural elements. It has connected to form one structural element such as composite bridge contains steel or precast girders and concrete slab. The relations between the different elements differes by modulus of elasticity and Poission's ration as partial or full interaction theory. Some recent contributions have taken the role of static loadings to the composite bridges. Newmark et al. [1] have derived a set of equations that represented the slip as a function of distance. During that contribution, a single second order differential equation was proposed for an element of beam to compensate the the equilibrium and compatibility equations regarding the axial force in the steel beam or concrete slab. It was concluded that the slip in beams with uniform spacing of shear connectors was larger than the slip values in beams with variable spacing. Burnet and Oehlers [5] suggested a design procedure for composite elements, and the variable was the degree of interaction and took into account the fracture that occurred in the shear connectors due to an increase in slip.

It was concluded that if the excessive slip and the consequent connection fracture can be related also to the materials plastic and elastic properties including the ductility requirements of beam. In addition, some recent contributions proposed the relation between the deflection rate and the relevant connection slips [6]. Al-Thebhawi [7] studied and analyzed composite steel-concrete beams as nonlinear by "finite element" numerical modelling procedure. The findings showing that the partially composite beam interaction has reduced the maximum of the normal strain at ultimate load compared with full interaction. Some contributions throughout the literature were implemented a three dimensional numerical modelling to inspect the role of composite beam in term of load deflection curves as by Bachachi [8] . Abdul Kaliq [9] studied the composite action in a composite bridge deck that the type of connectors that connected the steel girder and the deck slab was mechanically anchored. The results have indicated that all stresses based on the ACI code are within acceptable limits. Salahaldin [10] has studied the performance of a simple span beam with a plate at the top face 
of concrete beams connected by shear connectors that have worked as a partial interaction adopted a proposal by Johnson (1975).

Furthermore, some research programs within the past experience of this field proved that the partial interaction theory of shear connectors gives high deflection levels if compared with full interaction as cited by EL-Shihy et al. [11]. The current study tries to examine the full and partial interactions Al-Sabtea Bridge by implementing numerical modelling using finite element software "ANSYS".

\section{Model Generation}

The model generations by finite element passing throughout the three stages by using ANSYS software. The first step is building the model geometry and apply load to support conditions. The second run and find the results by post-processing, the last step is to draw specific nodes or elements from the time history of the select node [12]. All structural elements of the composite bridge that adopt the present study are simulated using the finite elements tool by ANSYS to analyze the composite plate girder. Different element types are selected, such as SOLID65 to concrete, "LINK180 " to reinforcing steel, COMBIN 39 for channels representing the shear connectors and "SHELL181" to girders that made of steel, and "SOLID185" to supports. "CONTA-174" as well as "TARGE 170" as an interfacing element and "BEAM188" to bracing domains, the model shown in Figures 1 and 2.

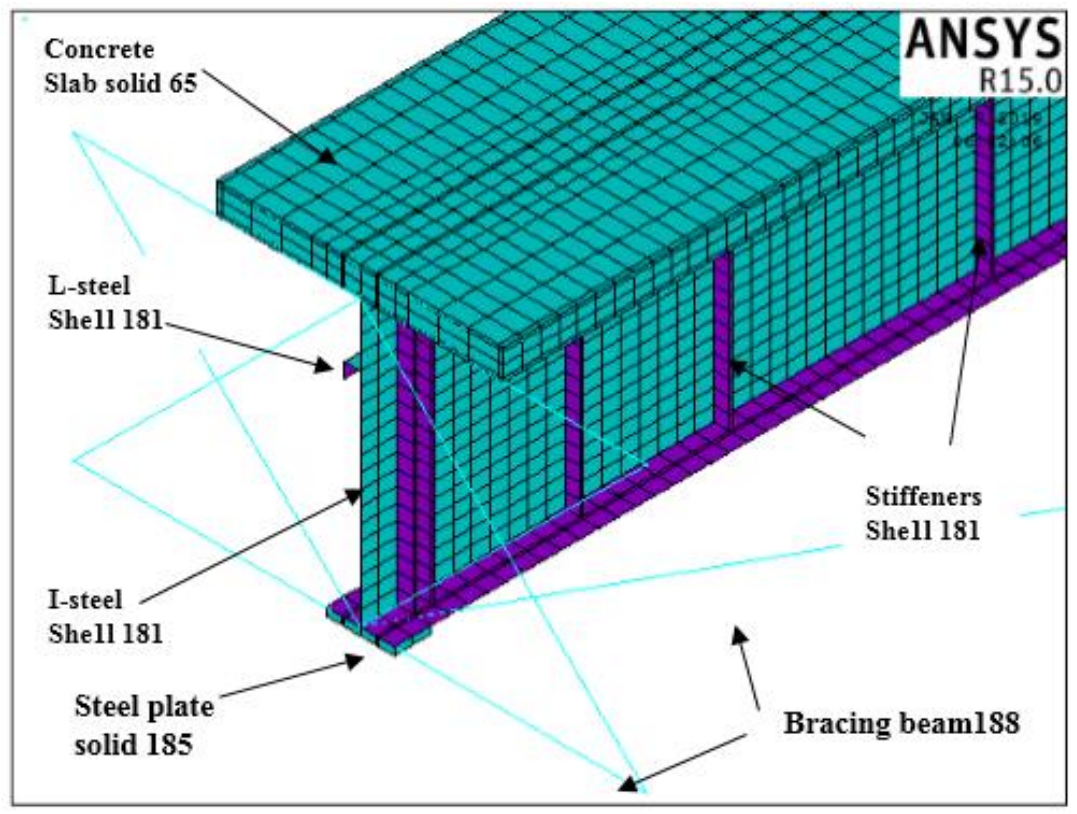

Figure 1. Element model for composite plate girder.

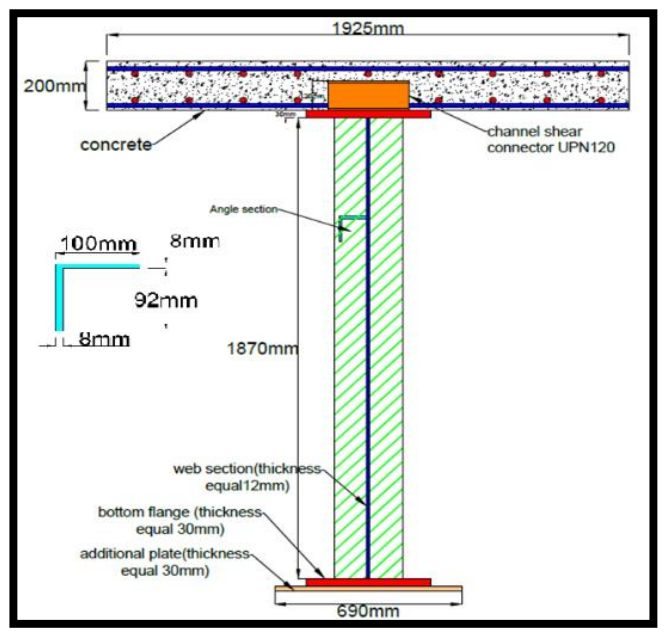

Figure 2. Steel sections and concrete slabs make up a composite beam. 
Element of concrete. The element type has been selected for concretes, which has been cracking and crushes capabilities. In this study, element of brick that is three-dimensional using (8) "nodes" are modelled to represent concrete (SOLID 65 in "ANSYS software") as illustrated in Figure 3 [13].

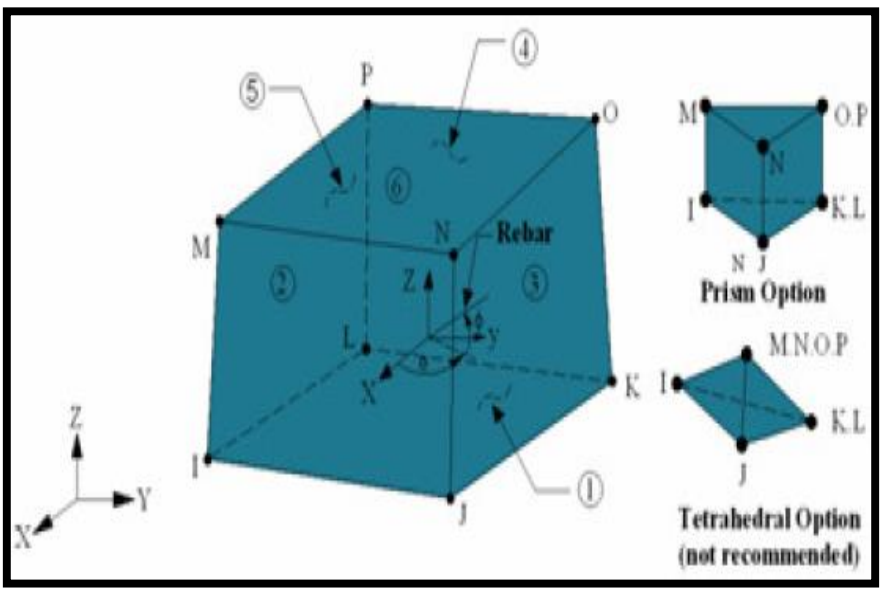

Figure 3. SOLID65 element geometry.

Steel girder element. The (4) nodes "shell element 181" was used within the current study to represent, the translation of all the zxes (x, y and $\mathrm{z}$ ) was enabled to get good compatibility with other elements [13]. Figure 4(a,b) shows the coordinate system, the geometry and node locations for such elements. The steel girder model is shown in Figure 4c.

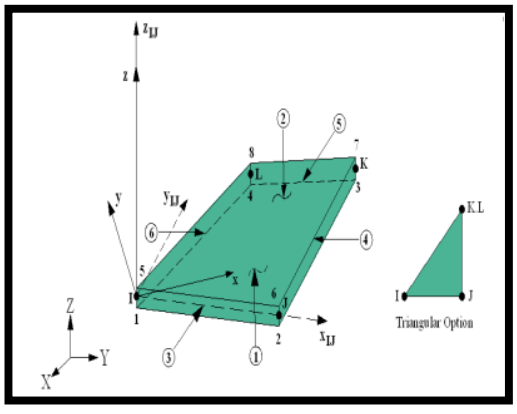

(a)

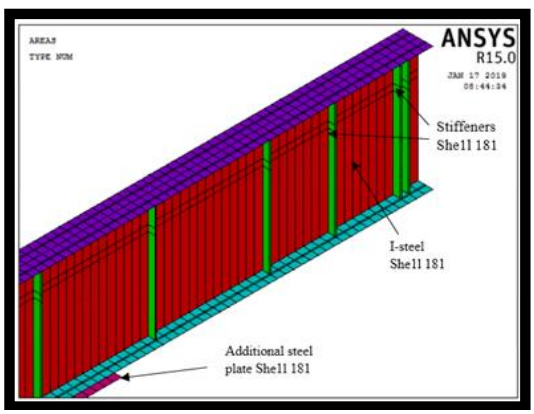

(b)

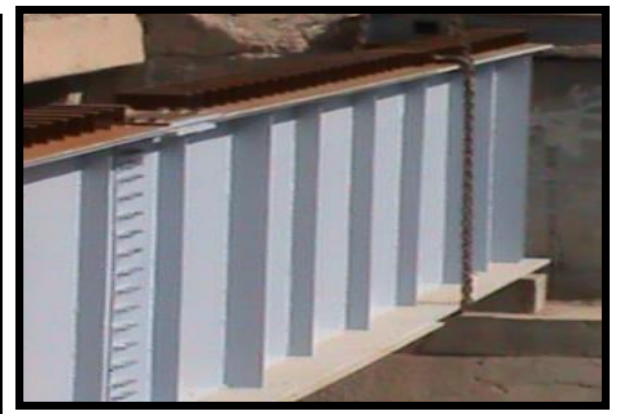

(c)

Figure 4. $(a, b)$ The geometry of "SHELL181" [13], (c) Actual steel girder.

Elements of steel plate. The steel plates adopt "SOLID185". The element is provided with (8) nodes with three degrees of freedom at each node, the geometry of elements as shown in Figure 5 [13].

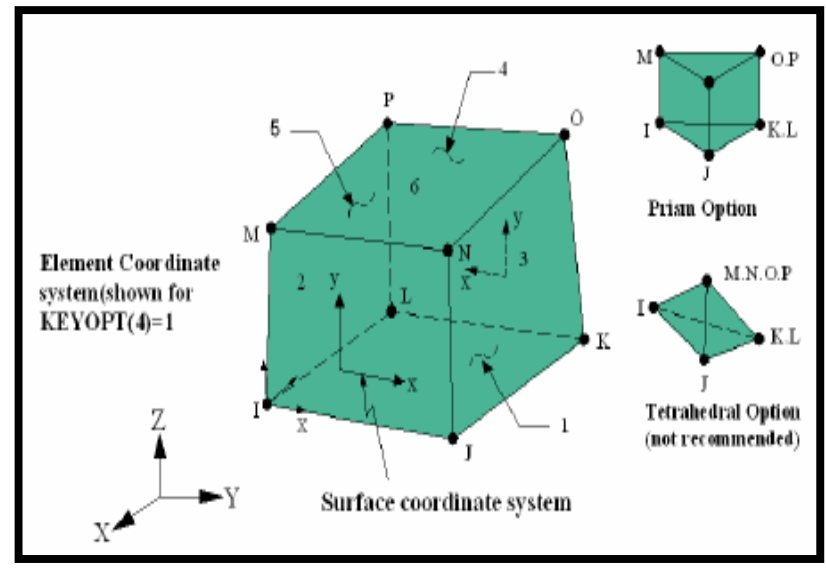

Figure 5. SOLID185 geometry [13]. 
Shear connectors element. Nonlinear springs elements "COMBIN39" are utilized to represent the "channel shear connectors". Element "COMBIN39" is unidirectional with the capabilities of loaddeflection that is nonlinear [14]. The element geometry is shown in Figure 6. The curve Points (D1, F1, etc.) denote the forces versus relative translation for the structure analyses. These data adopt in the present study of data from the experimental channel by push-out test and get as load (shear)-slips.

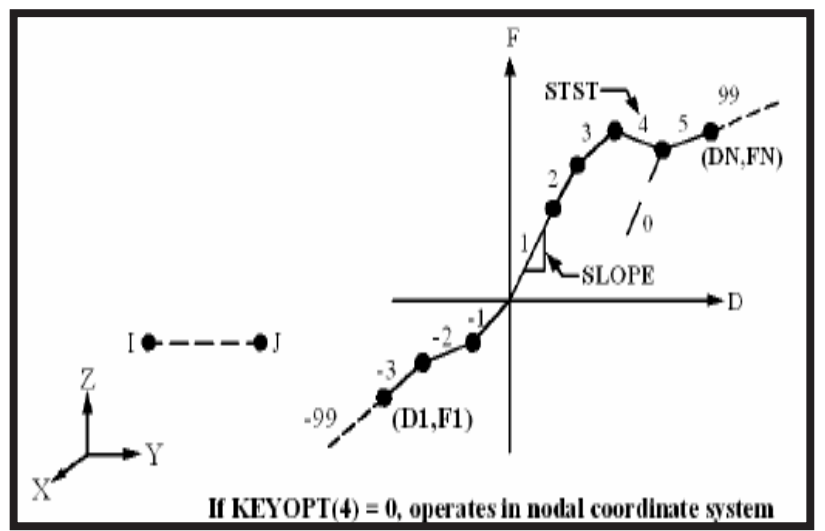

(a)

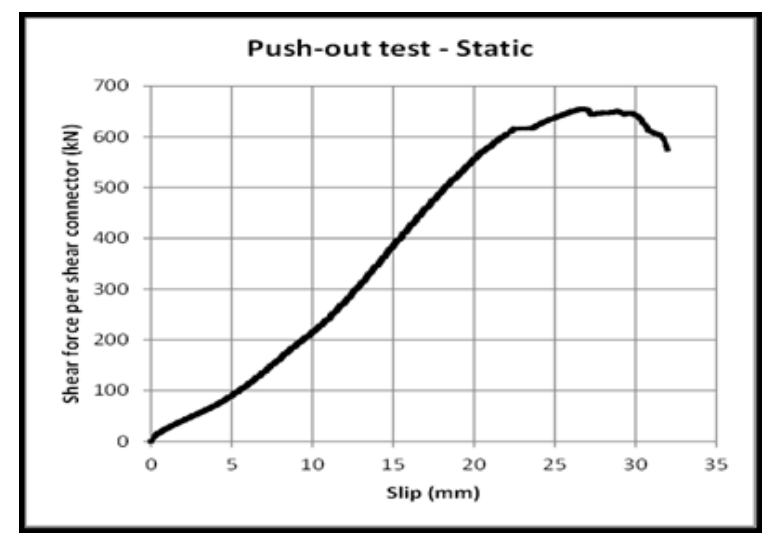

(b)

Figure 6. (a) COMBIN39 geometry [13]. (b) Load-displacement behavior under monotonic loading.

Element of reinforcement. Reinforcement has been embedded in the concrete deck slab, which is simulated by adopting LINK180 element. The LINK180 is a spar element as shown in Figure 7

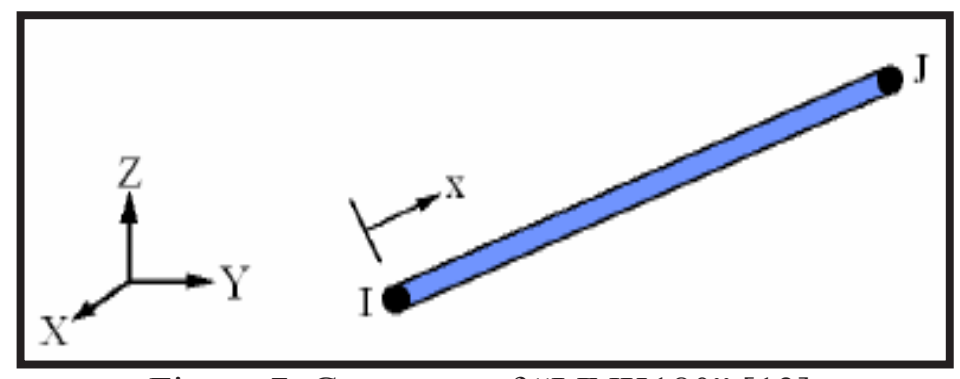

Figure 7. Geometry of "LINK180" [13].

Interface surface element. An element of three-dimensional nonlinear surfaces-to-surfaces as (CONTA-174 and TARGE 170) is adapted to model the nonlinear performance of the interface surface behavior among the concrete and steel girder. The two boundaries of these element types as form, contact, slid and deformable surface have taken as contact surfaces CONTA -174 and the other as a target surface TARGE-170, the elements as shown in Figure 8 [13].

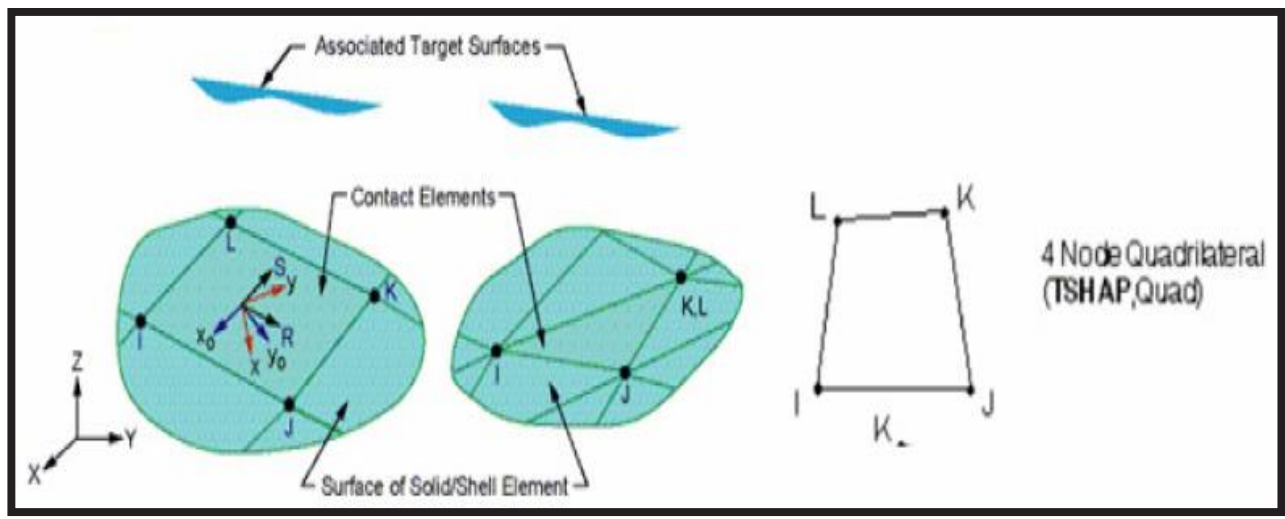

Figure 8. "CONTA-174" and "TARGE 170" geometry [13]. 
Element of bracing. Element beam 188 selects to model the bracing between the bottom steel girders as shown in Figure 9. This element is compatible for applications of linear, large rotation, and/or large strain nonlinear.

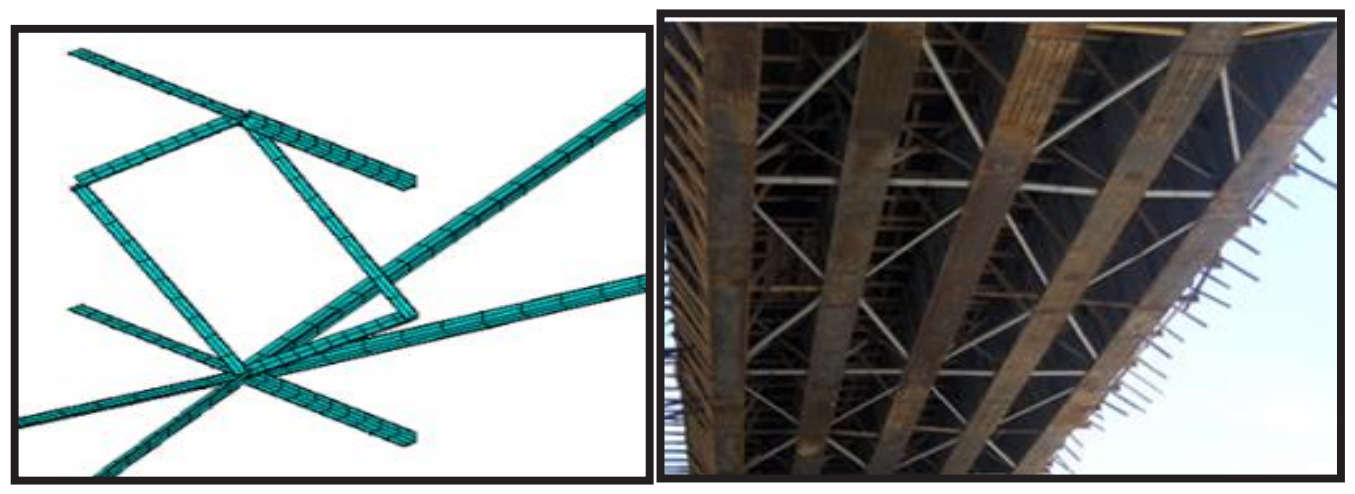

(a)

(b)

Figure 9. (a) BEAM188 geometry [13], (b) bracing in actual cases

\section{Materials Modeling}

The real properties of materials have been input in the ANSYS software including Poisson's ratio and modulus of elasticity.

Modeling. Homogeneous and isotropic are assumed for concrete material. The stress-strain of concrete to behave as nonlinear adopted by Desayi and Krishnan [14] is considering that has shown in Figure 10 [15].

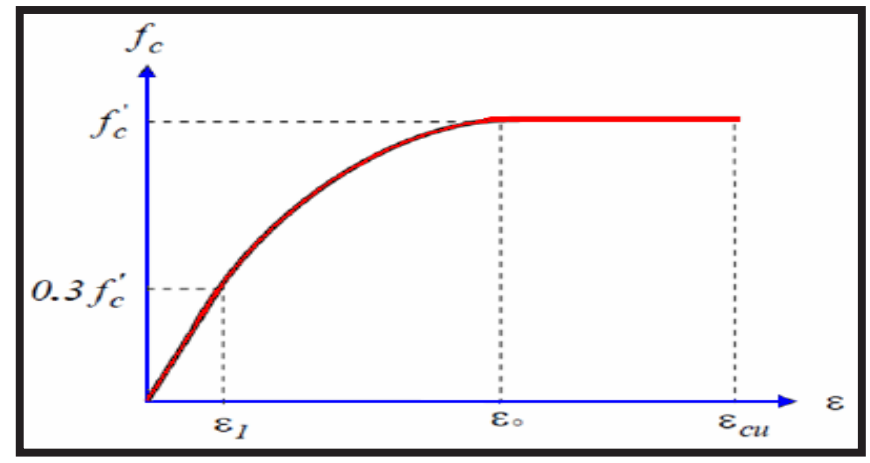

Figure 10. Concrete constitutive relation [17].

$\mathrm{E}_{\mathrm{c}}=4700 \sqrt{\mathrm{f}^{\prime}}$

In which:

$\mathrm{f}^{\prime}{ }_{\mathrm{c}}=$ "compressive strength" of concrete in $\mathrm{N} / \mathrm{mm}^{2}$

$\mathrm{E}_{\mathrm{c}}=$ elasticity modulus of concrete $\mathrm{N} / \mathrm{mm}^{2}$

$\mathrm{f}_{\mathrm{c}}=\varepsilon \mathrm{E}_{\mathrm{c}} \quad$ for $\quad 0 \leq \varepsilon \leq \varepsilon_{1}$

$\mathrm{f}_{\mathrm{c}}=\frac{\varepsilon \mathrm{E}_{\mathrm{c}}}{1+\left(\frac{\varepsilon}{\varepsilon_{\circ}}\right)^{2}}$ for $\varepsilon_{1} \leq \varepsilon \leq \varepsilon_{\text {。 }}$

$\mathrm{f}_{\mathrm{c}}=\mathrm{f}_{\mathrm{c}}{ }^{\prime} \quad$ for $\varepsilon_{\circ} \leq \varepsilon \leq \varepsilon_{\mathrm{cu}}$

$\varepsilon_{1}=\frac{0.3 f_{c}}{E_{c}}$ (Hooke's law)

$\varepsilon_{\circ}=\frac{2 f_{c}}{E_{c}}$

$\varepsilon_{1}=$ Strain of $\left(0.3 f^{\prime}{ }_{c}\right)$.

$\varepsilon_{\circ}=$ strain level at peck. 
$\varepsilon_{c u}=$ ultimate strain

Multi-linear curves are used to aid in the convergence of nonlinear solution algorithms.

Steel girder. The performance of stress- strai- has supposed to be bilinear as showing in Figure 12 [16]. The modulus of strain hardening $\left(E_{t}\right)$ is established to be $\left(0.03 E_{s}\right)$ [17].

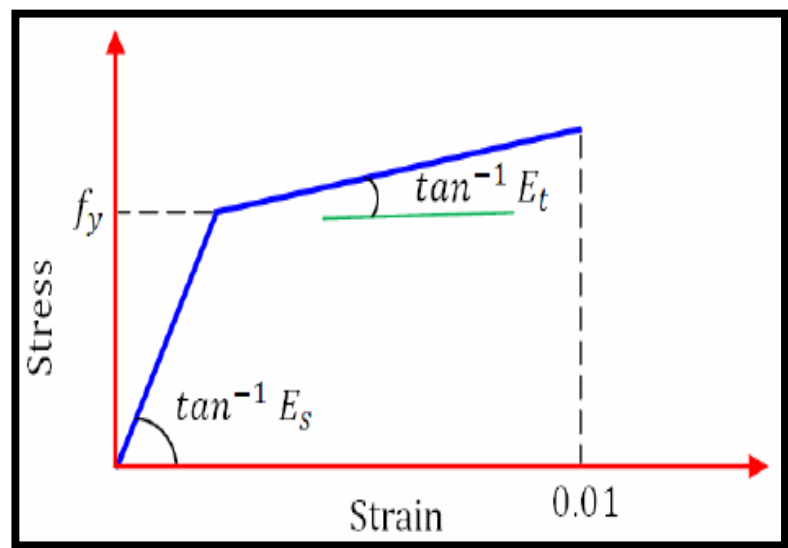

Figure 11. Bilinear stress-strain relationship of steel [16].

Interface surface finite element model. An element of three-dimensional nonlinear surfaces-tosurfaces as (CO NTA-174 and TARGE 170) is adapted to represent the nonlinear performance of the "interface surface behavior" among the concrete and steel girder. The two boundaries of these element types as form, contact, slid, and the deformation surface has been established as contact surfaces "CONTA-174" in addition to "TARGE-170" [13]. The mechanical properties of all components such as deck concrete slab, steel girder, shear connectors, and steel reinforcements as actual from the design criteria of the bridge are listed in Table 1.

Table 1. Properties of material.

\begin{tabular}{ccc}
\hline Material Type & Parameter & Value \\
\hline \multirow{3}{*}{ Concrete } & $f c^{\prime}$ & 28 \\
& $E_{c}$ & 25000 \\
& $v_{s}$ & 0.15 \\
\hline \multirow{3}{*}{ Steel girder } & $f_{y}$ & 319 \\
& $E_{S}$ & 385 \\
& $v_{s}$ & 200000 \\
Reinforcement & $E_{S}$ & 0.2 \\
\hline \multirow{3}{*}{ Steel Plate } & $f_{y}$ & 200000 \\
& $v_{s}$ & 0.3 \\
\hline \multirow{2}{*}{ Shear } & $f_{y}$ & 319 \\
Connector & $E_{S}$ & 200000 \\
& $v_{s}$ & 0.3 \\
\hline Contact surface & $f_{y}$ & 319 \\
& $E_{S}$ & 200000 \\
& $v_{s}$ & 0.3 \\
\hline
\end{tabular}

\section{Case study-Al Sabtia Bridge}

The bridge consisted of multi-steel girders that have a uniform geometry and are arranged in uniform spacing across the width of the bridge with three lanes road with a rigid traffic barrier, as shown in Figure 12. The bridge has exposure to the bombing, led to the collapse of the entire space of a length of $36 \mathrm{~m}$, and has space to rehabilitate. The bridge includes seven spans $252 \mathrm{~m}$ in length. 
The length of rehabilitated part is $36 \mathrm{~m}$, and the width is $21 \mathrm{~m}$. In the present study, the interior composite-concrete steel girder is selected because it represents the worst case. The center to center span of the composite bridge is $(35.75 \mathrm{~m})$ with $(200 \mathrm{~mm})$ deck slab thickness and reinforced by steel rebar of $(16 \mathrm{~mm})$ in diameter at $(200 \mathrm{~mm})$ center to center for bottom reinforcement and at the top reinforcement with a diameter of $(12 \mathrm{~mm})$ at $(200 \mathrm{~mm})$ center to center with top and bottom cover (35 and $25 \mathrm{~mm}$ ) respectively designed based on the AASHTO ASD. The supports conditions at the ends as shown in Figure 13 represent aq simply supported composite plate girder.
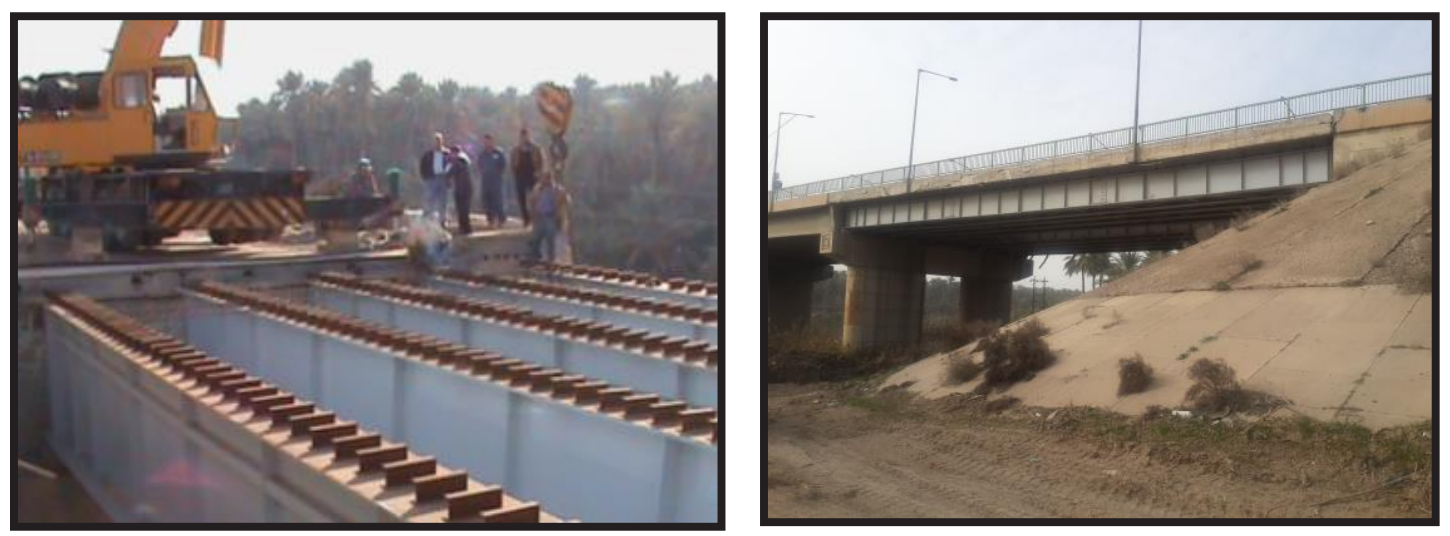

Figure 12. Al SABTIA Bridge.

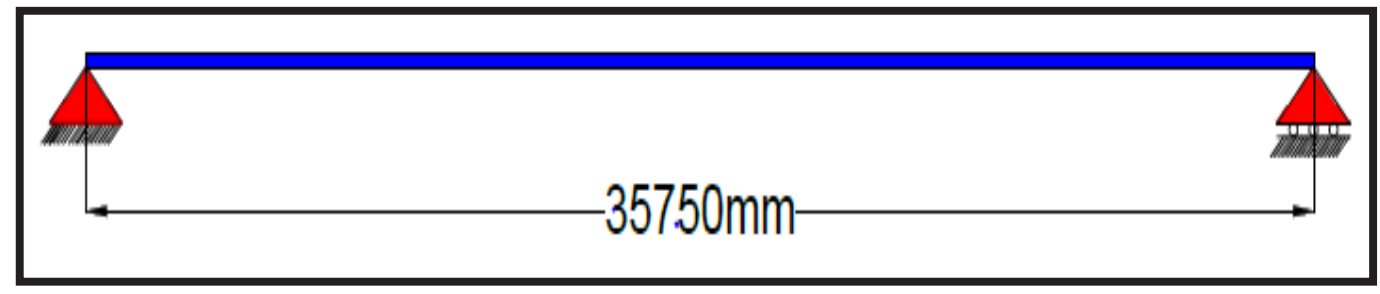

Figure 13. Simply supported bridge span.

\section{Loads Application}

That applied at the top of deck Slab Bridge in accordance with the Iraq bridge specification [18]. The load kinds that adapt in this investigation are listed below.

Non-composite dead load. The domain that represent the girders within the current study is considered as a "body force" which have $78.5 \mathrm{kN} / \mathrm{m}^{3}$ density (Structural steel). On the other hand, the concrete deck is represented as a uniformly distributed loads considering the density of concrete as $\left(25 \mathrm{kN} / \mathrm{m}^{3}\right)$.

Superimposed dead load. The super imposed dead loads are usually represented by the concrete deck load which transformed to an equivalent area. In addition, the asphalt is also treated as a super imposed dead load with a density $\left(22 \mathrm{kN} / \mathrm{m}^{3}\right)$ and thickness of $(80 \mathrm{~mm})$.

Live load. During the current study, the live loads are assumed according to the Iraqi standard specifications. The carriage way width during the entire analyses is $7.5 \mathrm{~m}$ including three traffic lanes of $(2,5 \mathrm{~m})$. however, the following procedure is followed"

- Lane Load: Since the loaded length of the lane is $35.75 \mathrm{~m}$, the "Uniform Distributed Load (UDL)" is $23 \mathrm{~N} / \mathrm{mm}$ per lane and "Knife Edge Load (KEL)" equals $40.18 \mathrm{~N} / \mathrm{mm}$ per lane. The representation of lane load is done by "combined element 39 model (MS3)" utilizing solid "element model (MS3L)" as shown in Figure 14c and Figure 15.

- Military Loading: Since the carriage way is less than $8.3 \mathrm{~m}$, the joint is established as "onelane military loading joint" considering "full foot-path loading". 
a) The "Tracked Vehicles Class 100": such vehicles are represented by "combined element 39 model (MS3)" utilizing solid "element model (MS3L)" as shown in Figure 14c and Figure 15.

b) The "Wheeled Vehicles Class 100": as shown in Figure $14 \mathrm{~b}$ and Figure 17, such vehicles loads perform loading up to yielding. This load is represented by "combined element 39 models (MS1") to the channel shear connector using "solid element model (MS1W)" as shown in Table 2 and Appendix-A.

\section{Static Analysis Results - Iraq Specifications}

Partial and full interaction theories have been adopted to analyze the composite steel girders and consider the interior composite steel girder due to represent the worst-case and advised by Iraqi road specification. The calculations for all models based on the worst location of the maximum moment, deflection, and comparing these results with code and hand out calculations to check. The work has divided this work into five groups by representing "channel shear connector" as "combined element 39" expect group (B) by using "channel shear connector" as a "solid element for model (MS1W, MS1T, and MS1L)" as shown in Table 2 and Table 3.

The load-deflection performance of the composite plate girder has been achieved from the finite element. In Figures 15 and 16a and under all applied loads, the deflection distance along the composite girder at the bottom of the steel girder is for (MS1, MS2, and MS3). It is obviuse that when the load increased, the consequent accumulative deflection is increased (especially at the bottom center). It is constant, so the higher that deflection in (MS2) because of this type of load represents this worst case of loading. It is also reported that the deflection response at the bottom steel girder to "MS2" load case is more than "MS1" by 95 and more than "MS3" by $13.6 \%$.

Figures 15 and 16b compares the deflection distance along composite girder at the bottom of the steel girder for all applied loading (MS1, MS2, and MS3) and (MS1W, MS2T, and MS3L) representing "channel shear connector" as "combined element 39" and "solid element" respectively, however, the results showed that the difference is rather low $(2.5-3.7 \%)$.

Table 2. Groups of models for all bridge girder according of Iraqi road specification.

\begin{tabular}{|c|c|c|c|}
\hline Group & Model & Load & Spacing between shear connector \\
\hline \multirow{3}{*}{ A } & MS1 & Wheeled Vehicles Class 100 & 250 and $300 \mathrm{~mm} \mathrm{c} / \mathrm{c}$ \\
\hline & MS2 & Tracked Vehicles Class 100 & 250 and $300 \mathrm{~mm} \mathrm{c} / \mathrm{c}$ \\
\hline & MS3 & Lane Load & 250 and $300 \mathrm{~mm} \mathrm{c} / \mathrm{c}$ \\
\hline \multirow{6}{*}{ B } & MS1 & Wheeled Vehicles Class 100 & 250 and $300 \mathrm{~mm} \mathrm{c} / \mathrm{c}$ \\
\hline & MS2 & Tracked Vehicles Class 100 & 250 and $300 \mathrm{~mm} \mathrm{c} / \mathrm{c}$ \\
\hline & MS3 & Lane Load & 250 and $300 \mathrm{~mm} \mathrm{c} / \mathrm{c}$ \\
\hline & MS1W & Wheeled Vehicles Class 100 & 250 and $300 \mathrm{~mm} \mathrm{c} / \mathrm{c}$ \\
\hline & MS2T & Tracked Vehicles Class 100 & 250 and $300 \mathrm{~mm} \mathrm{c} / \mathrm{c}$ \\
\hline & MS3L & Lane Load & 250 and $300 \mathrm{~mm} \mathrm{c} / \mathrm{c}$ \\
\hline \multirow{3}{*}{$\mathrm{C}$} & MS1 & Wheeled Vehicles Class 100 & 250 and $300 \mathrm{~mm} \mathrm{c} / \mathrm{c}$ \\
\hline & MS1A & Wheeled Vehicles Class 100 & 500 and $600 \mathrm{~mm} \mathrm{c} / \mathrm{c}$ \\
\hline & MS1B & Wheeled Vehicles Class 100 & $\begin{array}{l}\text { Full interaction between concrete and steel } \\
\text { girder }\end{array}$ \\
\hline \multirow{3}{*}{$\mathrm{D}$} & MS2 & Tracked Vehicles Class 100 & 250 and $300 \mathrm{~mm} \mathrm{c} / \mathrm{c}$ \\
\hline & MS2A & Tracked Vehicles Class 100 & 500 and $600 \mathrm{~mm} \mathrm{c} / \mathrm{c}$ \\
\hline & MS2B & Tracked Vehicles Class 100 & $\begin{array}{l}\text { Full interaction between concrete and steel } \\
\text { girder }\end{array}$ \\
\hline \multirow{3}{*}{$\mathrm{E}$} & MS3 & Lane Load & 250 and $300 \mathrm{~mm} \mathrm{c} / \mathrm{c}$ \\
\hline & MS3A & Lane Load & 500 and $600 \mathrm{~mm} \mathrm{c} / \mathrm{c}$ \\
\hline & MS3B & Lane Load & $\begin{array}{l}\text { Full interaction between concrete and steel } \\
\text { girder }\end{array}$ \\
\hline
\end{tabular}


Table 3. Type of loading base on Iraqi specification.

\begin{tabular}{|c|c|}
\hline Model & Type of Loading \\
\hline MS1 & $\begin{array}{c}\text { Wheeled Vehicles Class } 100 \text { using a representation of channel shear } \\
\text { connector as COMBIN } 39 \text { element with spacing between shear connector } \\
250 \text { and } 300 \mathrm{~mm} \mathrm{c} / \mathrm{c}\end{array}$ \\
\hline MS2 & $\begin{array}{c}\text { Tracked Vehicles Class } 100 \text { using a representation of channel shear } \\
\text { connector as COMBIN } 39 \text { element with spacing between shear connector } \\
250 \text { and } 300 \mathrm{~mm} \mathrm{c} / \mathrm{c}\end{array}$ \\
\hline MS3 & $\begin{array}{l}\text { Lane Load using a representation of channel shear connector as COMBIN } \\
39 \text { element with spacing between shear connector } 250 \text { and } 300 \mathrm{~mm} \mathrm{c} / \mathrm{c}\end{array}$ \\
\hline MS1W & $\begin{array}{l}\text { Wheeled Vehicles Class } 100 \text { using represented of channel shear connector } \\
\text { as solid element for model Spacing between shear connector } 250 \text { and } 300 \\
\mathrm{~mm} \mathrm{c/c}\end{array}$ \\
\hline MS2T & $\begin{array}{l}\text { Tracked Vehicles Class } 100 \text { using represented of channel shear connector as } \\
\text { solid element for model Spacing between shear connector } 250 \text { and } 300 \mathrm{~mm} \\
\mathrm{c} / \mathrm{c}\end{array}$ \\
\hline MS3L & $\begin{array}{l}\text { Lane Load using represented of channel shear connector as solid element for } \\
\text { model Spacing between shear connector } 250 \text { and } 300 \mathrm{~mm} \mathrm{c} / \mathrm{c}\end{array}$ \\
\hline MS1A & $\begin{array}{c}\text { Wheeled Vehicles Class } 100 \text { using a representation of channel shear } \\
\text { connector as COMBIN } 39 \text { element with spacing between shear connector } \\
500 \text { and } 600 \mathrm{~mm} \mathrm{c} / \mathrm{c}\end{array}$ \\
\hline MS1B & $\begin{array}{c}\text { Wheeled Vehicles Class } 100 \text { using a representation of channel shear } \\
\text { connector as COMBIN } 39 \text { element full interaction between concrete and } \\
\text { steel girder }\end{array}$ \\
\hline $\mathrm{MS} 2 \mathrm{~A}$ & $\begin{array}{c}\text { Tracked Vehicles Class } 100 \text { using a representation of channel shear } \\
\text { connector as COMBIN } 39 \text { element with spacing between shear connector } \\
500 \text { and } 600 \mathrm{~mm} \mathrm{c} / \mathrm{c}\end{array}$ \\
\hline MS2B & $\begin{array}{c}\text { Tracked Vehicles Class } 100 \text { using a representation of channel shear } \\
\text { connector as COMBIN } 39 \text { element with Full interaction between concrete } \\
\text { and steel girder }\end{array}$ \\
\hline MS3A & $\begin{array}{l}\text { Lane Load using a representation of channel shear connector as COMBIN } \\
39 \text { element with spacing between shear connector } 500 \text { and } 600 \mathrm{~mm} \mathrm{c} / \mathrm{c}\end{array}$ \\
\hline MS3B & $\begin{array}{l}\text { Lane Load using a representation of channel shear connector as COMBIN } \\
\qquad 39 \text { element with Full interaction }\end{array}$ \\
\hline
\end{tabular}

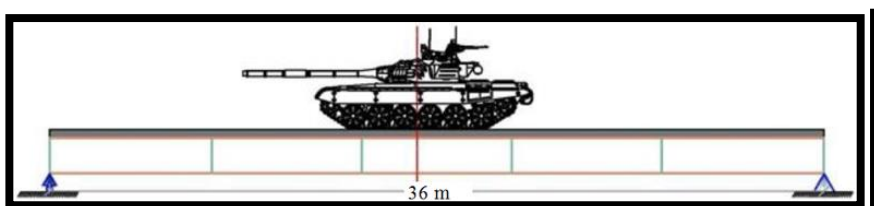

(a)"Tracked Vehicles"'

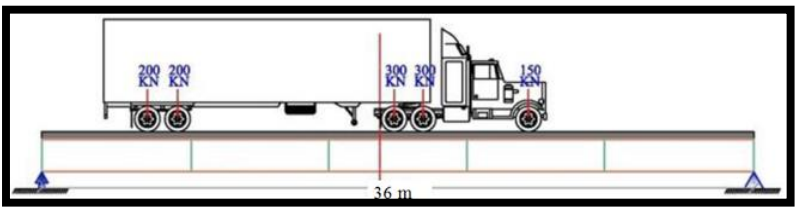

(b) "Wheel Vehicles"

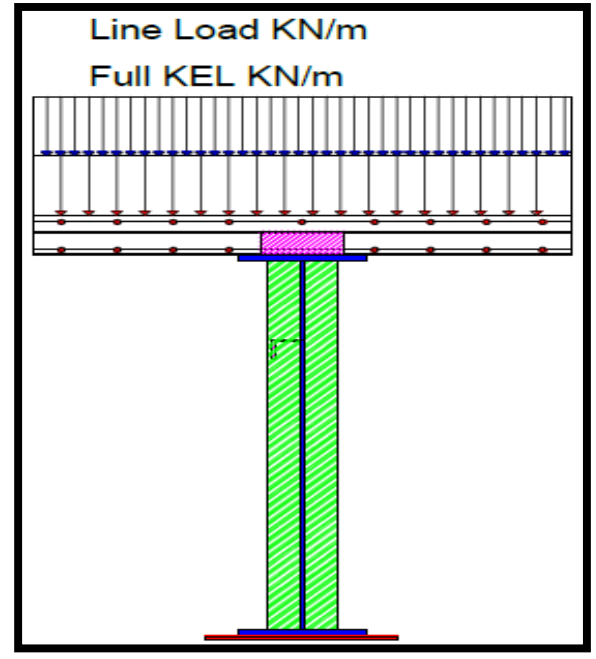

(c) "(UDL) and (KEL)"

Figure 14. Load case, (a) Tracked Vehicles, (b) Wheel Vehicles, (c) (UDL) and (KEL) 


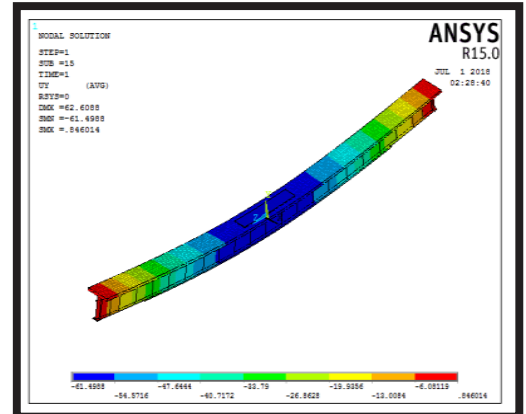

(a)

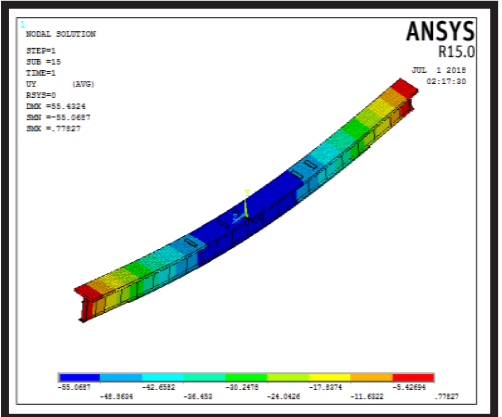

(b)

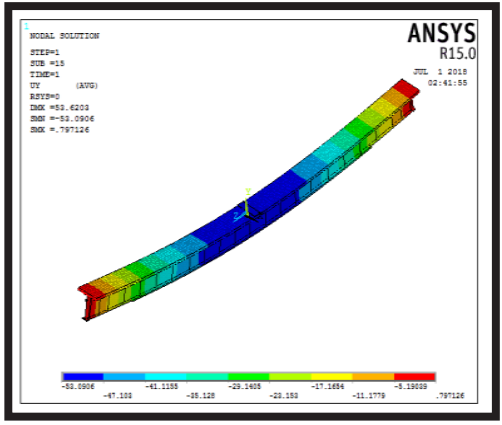

(c)

Figure 15. deflection pattern in states of a deflection curve, (a) MS1, (b) MS2, (c) MS3

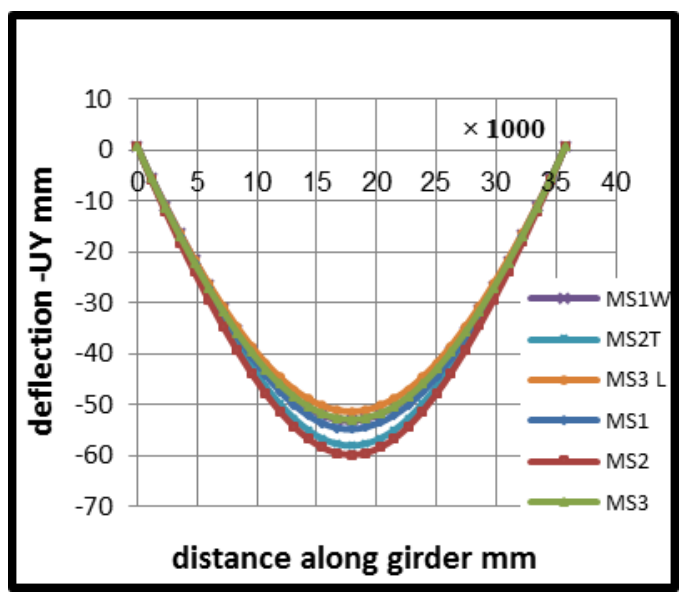

(a)

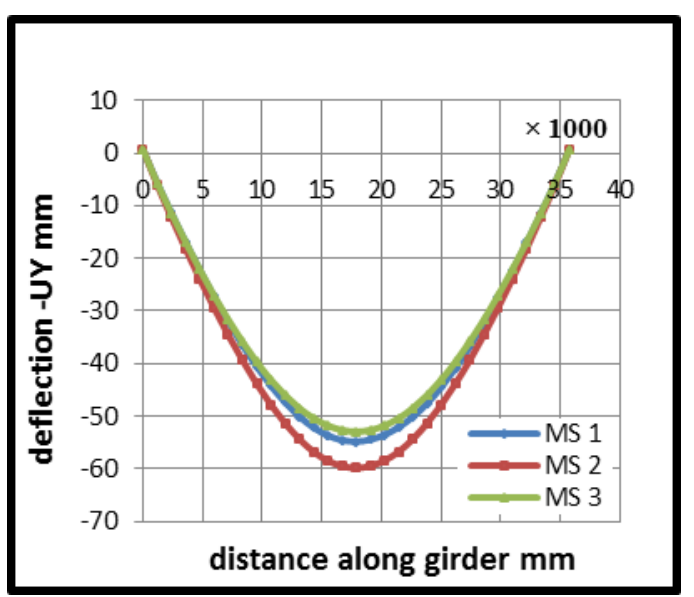

(b)

Figure 16. deflection at bottom steel girder for (a) group A, (b) for group B.

Figure 17a same condition of applied loading Figure 16a only (MS1) except that the center to center distance of channel shear connector become $(500$ and $600 \mathrm{~mm}$ ) in load case (MS1A), increase of shear connector spacing the slip becomes more, and the deflection become more. (Same performance in the case of applied MS2A and MS3A) as shown in Figure 17b and 17c. The response at bottom steel girder for load case (MS1A, MS2A, and MS3A) illustrated high levels if compared with those of (MS1, MS2, andMS3) are (10.29\%, 8.62\%, and 9.28\%) respectively.

The "full performance" of "slip distance" at the interfacing region for all applied load cases "MS1, MS2 and MS3" for composite steel girder are shown in Figures 18a and 19a. When the load is increased, the related slip is also increased at the midspan of the composite girder since it is accumulated starting from the centerline of such girder. The sign convention of the load was inversed for the load case "MS\#" since it is representing the worst case of loading started from centerline of girder under the symmetrical boundary condition.

In contrast, the slip response levels (between the bottom and the top steel girder) for load case "MS3" is more than for "MS1" by 21,4\% and more than "MS2" by $15.71 \%$. Figure 18b the slip along composite girder at the bottom of the steel girder for all applied loading (MS1, MS2, and MS3) and (MS1W, MS2T, MS3L) with using to represent "channel shear connector" as combined element 39 and "solid element", respectively, the difference in response with respect to slip is also rather small $(2.5-3.7 \%)$. 


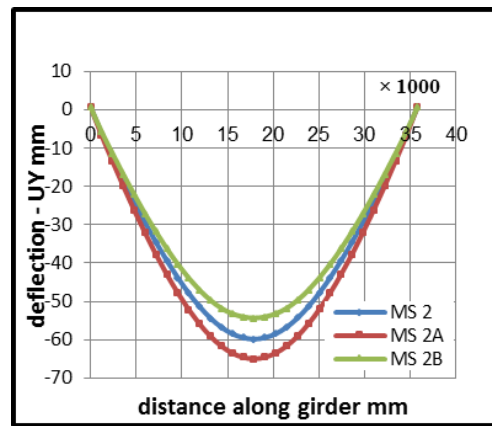

(a)

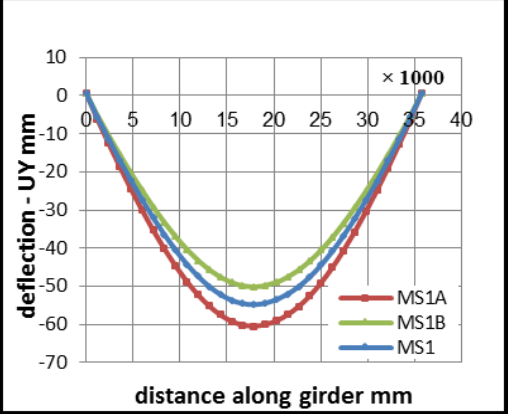

(b)

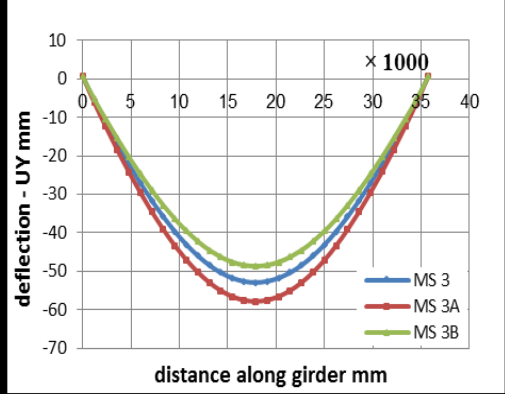

(c)

Figure 17. Deflection at bottom steel girder for (a) Group C, (b) For group D, (c) For group E.

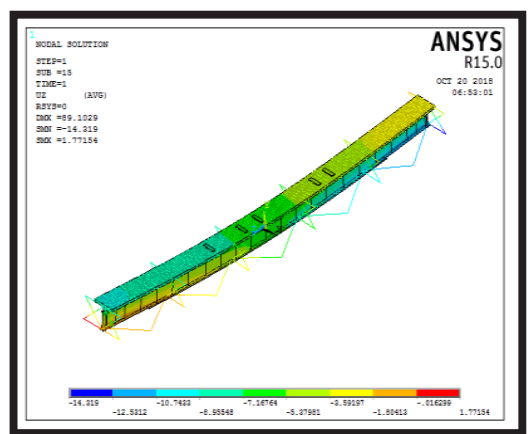

(a)

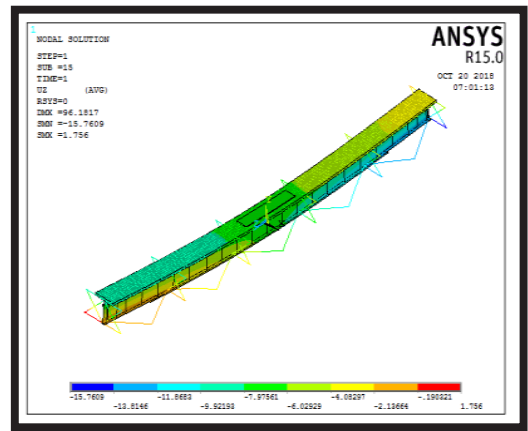

(b)

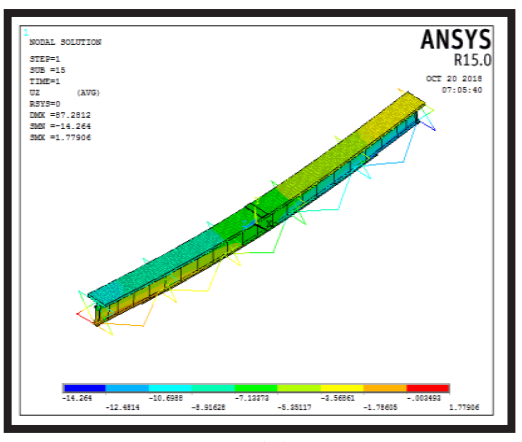

(c)

Figure 18. slip pattern, (a) MS1, (b) MS2, (c) MS3.

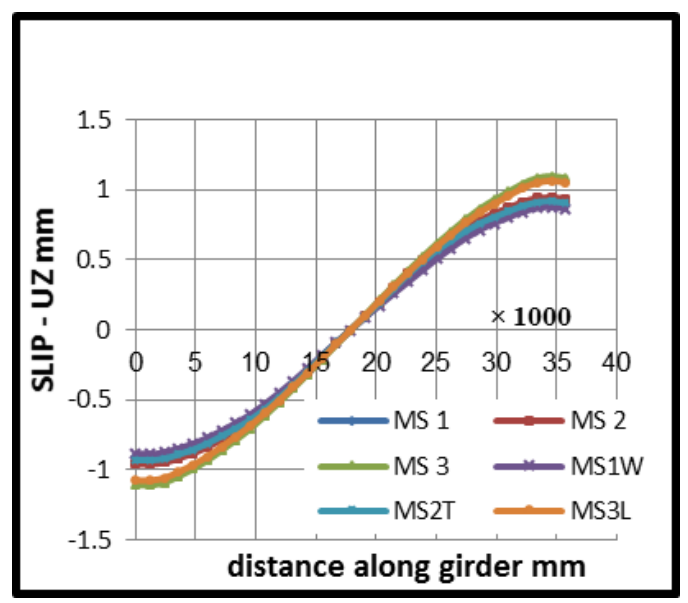

(a)

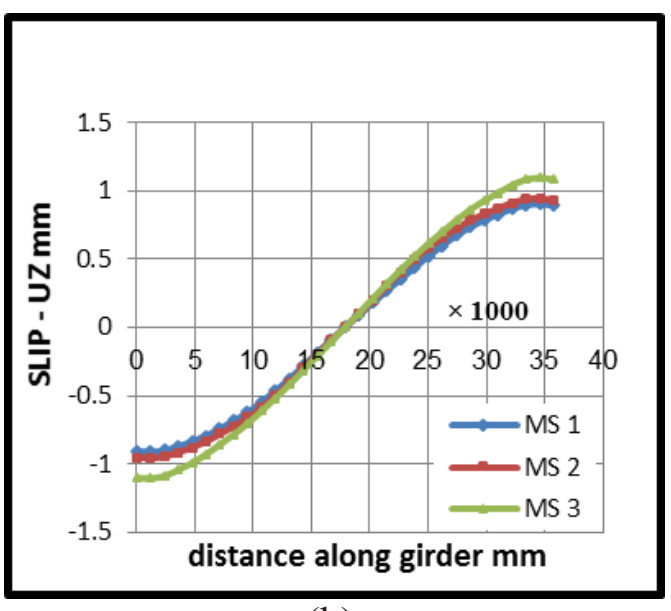

(b)

Figure 19. "Slip at interface" between steel gird and concrete er, (a) for group A, (b) for group B.

Figure 20a same condition of applied loads of Figure 16a only (MS1) excepts that the center to center distance of channel shear connector become (500 and $600 \mathrm{~mm}$ ) in load case (MS1A) increase of shear connector spacing the slip becomes more at the support that leads increase shear stress and shear flow. (Same performance in the case of applied (MS2A) and (MS3A) as shown in Figures 20b and 20c. The levels of slip response at the "interface" between steel girder and concrete for load case (MS1A, MS2A, and MS3A) are high if compared with load case (MS1, MS2, and MS3) are (322\%, $244 \%$, and $314 \%$ ) respectively. 


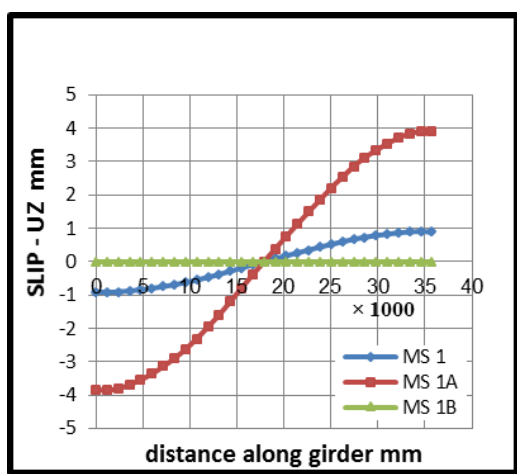

(a)

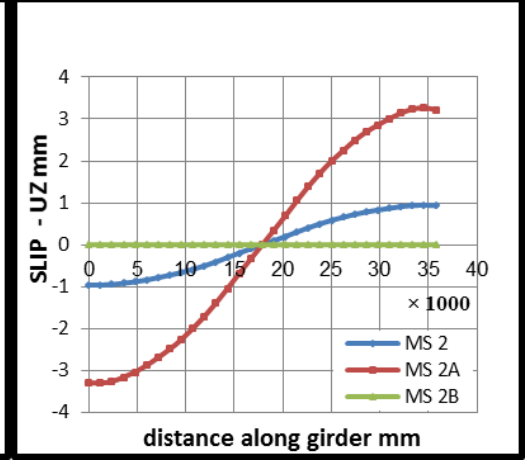

(b)

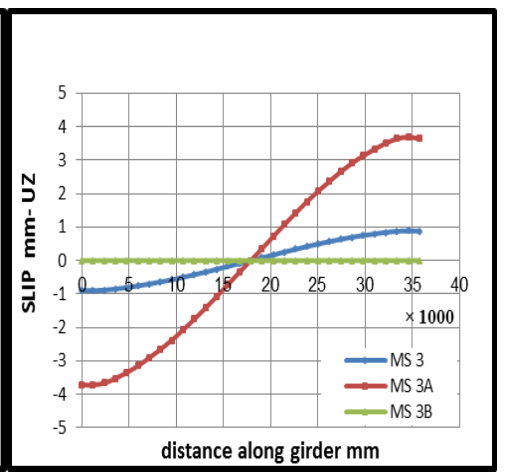

(c)

Figure 20. Slip at the interface between concrete and steel girder, (a) for group C, (b) for group D, (c) for group E.

\section{Conclusions}

The current study includes the numerical modelling of "SABTEA Bridge" using finite element software "ANSYS". Such modelling was performed by representing the actual dimensions as well as the mechanical properties. The following are some conclusions that can be drawn throughout the present study.

- Modeling of concrete by eight-node (brick element) and steel beam by four-node (shell element) and considering the effect of shear transfer give better accuracy in comparison with available experimental results of a "push-out" test under static load with a difference in the displacement results is small (5\%) in the value of maximum slip.

- Utilizing "COMBIN39" is very powerful for simulating "channel shear connectors" if compared with other the 3D solid types which need additional efforts for modelling. Since the number of shear connector is large, the difference in deflection response is rather small (2.5 $3.7 \%$ ). In addition, the number of elements and the related time is reduced because the used element is "combined element 39 ".

- The deflection profile distance along "composite girder" at the bottom of the steel girder to all load cases ant it is reported that the deflection response is increased if the load is increased. It is also noted that there is an increase in shear connector spacing the slip becomes more and the deflection become more. Deflection response "in bottom steel girder" for load case (Tracked Vehicles) is more than (Wheeled Military loading) by $9 \%$ and more than (lane loading) by $13.6 \%$.

- When the applied load increases the slip increases and becomes max. At the end of simply supported composite girder. The values of slip at interface between top steel girder and bottom of concrete load case (lane loading) larger than as compared with load case (Wheeled Military loading) $21.4 \%$ and larger than as compared with load case (Tracked Vehicles) $15 \%$.

- The deflection response is within the acceptable limits of AASHTO ASD.

- After performing the current analyses, the tested bridge is considered as "Safe" by taking large number of shear connectors into consideration.

\section{Reference}

[1] Newmark, N.M., 1951. Test and analysis of composite beams with incomplete interaction. Proceedings of society for experimental stress analysis, 9(1), pp.75-92.

[2] Yam, L.C.P. and Chapman, J.C., 1972. The inelastic behavior of continuous composite beams of steel and concrete. Institution of Civil Engrs, Pt2, Research \& Theory, 53(Proceeding).

[3] Abbas, A.L. and Hamood, Q.Y., 2018. Assessment of Al-Sabtea Bridge under the Effects of Static Loadings. Civil Engineering Journal, 4(11), pp.2680-2691. 
[4] Lam, D. and El-Lobody, E., 2001. Finite element modelling of headed stud shear connectors in steel-concrete composite beam. In Structural Engineering, Mechanics and Computation (pp. 401408). Elsevier Science.

[5] Burnet, M.J. and Oehlers, D.J., 2001. Fracture of mechanical shear connectors in composite beams.

[6] Gelfi, P. and Giuriani, E., 2003. Influence of Slab-Beam Slip on the Deflection of Composite Beams/Die Rolle des Schlupfes zwischen Platte und Balken bei der Durchbiegung von Verbundbalken. Restoration of Buildings and Monuments, 9(5), pp.475-490.

[7] Yao, Z., 2013. Nonlinear finite element analysis of reinforced concrete beams. HKU Theses Online (HKUTO).

[8] Bach chi, M. S. "Nonlinear Analysis of Composite Concrete-Steel Beams under Bending Loads by Finite Element Method". M.Sc. Thesis, University of Technology, 2007.

[9] Abdul Kaliq, 2011. Numerical Model Of Composite Bridge Decks. M.Sc. Thesis, University of Al-Nahrain.

[10] Salahaldin, A.I. and Hama, S.M., 2016. Nonlinear Behavior of Strengthened Steel-Concrete Composite Beams with Partial Interaction of Shear Connectors. Journal of Engineering, 22(8), pp.16-36.

[11] AM, EL Shihy, Shabaan HF, Al Kader HM, and Hassan in AI. "Effect of Partial Shear Connection on Strengthened Composite Beams with Externally Post-Tension Tendons." Journal of Material Science \& Engineering 06, no. 02 (2017). doi:10.4172/2169-0022.1000318.

[12] Abbas, A.L. and Hamood, Q.Y., 2018. Assessment of Al-Sabtea Bridge under the Effects of Static Loadings. Civil Engineering Journal, 4(11), pp.2680-2691.

[13] Abbas, A.L. and Hamood, Q.Y., 2018. Assessment of Al-Sabtea Bridge under the Effects of Static Loadings. Civil Engineering Journal, 4(11), pp.2680-2691.

[14] Abbas, A.L. and Hamood, Q.Y., 2018. Assessment of Al-Sabtea Bridge under the Effects of Static Loadings. Civil Engineering Journal, 4(11), pp.2680-2691.

[15] Hognestad, E., 1951. Study of combined bending and axial load in reinforced concrete members. University of Illinois at Urbana Champaign, College of Engineering. Engineering Experiment Station.

[16] Ibrahim, A.M., Mohaisen, S.K. and Ahmed, Q.W., 2012. Finite element modeling of composite steel-concrete beams with external prestressing. International Journal of Civil \& Structural Engineering, 3(1), pp.101-116.

[17] Abbas, A.L., 2010. Non-linear analysis of reinforced concrete beams strengthened with steel and CFRP plates. Diyala Journal of Engineering Sciences, pp.249-256.

[18] Iraq standard specifications for road and bridge, 1978. Ministry of housing and construction, state of organization of roads and bridges, Baghdad, Iraq. 